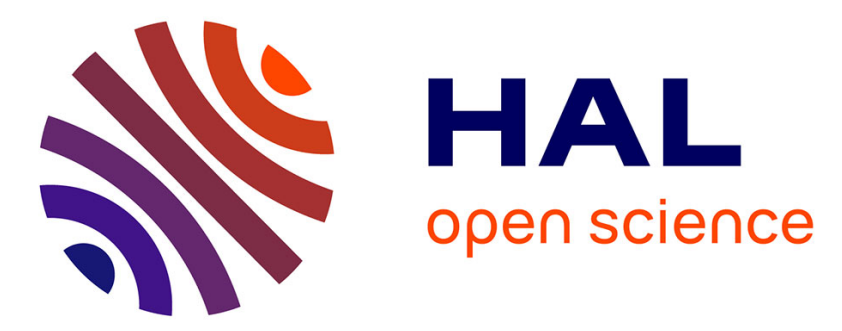

\title{
Joint experimental and numerical study of the influence of flame holder temperature on the stabilization of a laminar methane flame on a cylinder
}

Maxence Miguel-Brebion, Daniel Mejia, Pradip Xavier, Florent Duchaine, Benoît Bédat, Laurent Selle, Thierry Poinsot

\section{To cite this version:}

Maxence Miguel-Brebion, Daniel Mejia, Pradip Xavier, Florent Duchaine, Benoît Bédat, et al.. Joint experimental and numerical study of the influence of flame holder temperature on the stabilization of a laminar methane flame on a cylinder. Combustion and Flame, 2016, 172, pp.153-161. 10.1016/j.combustflame.2016.06.025 . hal-01557859

\section{HAL Id: hal-01557859 \\ https://hal.science/hal-01557859}

Submitted on 6 Jul 2017

HAL is a multi-disciplinary open access archive for the deposit and dissemination of scientific research documents, whether they are published or not. The documents may come from teaching and research institutions in France or abroad, or from public or private research centers.
L'archive ouverte pluridisciplinaire HAL, est destinée au dépôt et à la diffusion de documents scientifiques de niveau recherche, publiés ou non, émanant des établissements d'enseignement et de recherche français ou étrangers, des laboratoires publics ou privés. 


\section{Open Archive TOULOUSE Archive Ouverte (OATAO)}

OATAO is an open access repository that collects the work of Toulouse researchers and makes it freely available over the web where possible.

This is an author-deposited version published in : http://oatao.univ-toulouse.fr/ Eprints ID : 18025

To link to this article : DOI:10.1016/j.combustflame.2016.06.025

URL :http://dx.doi.org/10.1016/j.combustflame.2016.06.025

To cite this version : Miguel-Brebion, Maxence and Mejia, Daniel and Xavier, Pradip and Duchaine, Florent and Bédat, Benoît and Selle, Laurent and Poinsot, Thierry Joint experimental and numerical study of the influence of flame holder temperature on the stabilization of a laminar methane flame on a cylinder. (2016) Combustion and Flame, vol. 172. pp. 153-161. ISSN 0010-2180

Any correspondence concerning this service should be sent to the repository administrator: staff-oatao@listes-diff.inp-toulouse.fr 


\title{
Joint experimental and numerical study of the influence of flame holder temperature on the stabilization of a laminar methane flame on a cylinder
}

\author{
M. Miguel-Brebion ${ }^{\mathrm{a}, *}$, D. Mejia ${ }^{\mathrm{a}}$, P. Xavier ${ }^{\mathrm{a}}$, F. Duchaine ${ }^{\mathrm{b}}$, B. Bedat ${ }^{\mathrm{a}}$, L. Selle ${ }^{\mathrm{a}}$, T. $_{\text {Poinsot }}^{\mathrm{a}}$ \\ a Institut de Mécanique des Fluides de Toulouse (IMFT), Université de Toulouse, CNRS-INPT-UPS, Toulouse, France \\ ${ }^{\mathrm{b}}$ CERFACS, CFD team, 42, avenue Coriolis, Toulouse cedex 01 31057, France
}

Keywords:

DNS

Conjugate heat transfer

Analytical chemistry

Radiative transfer

Stabilization

Premixed flame

\begin{abstract}
A B S T R A C T
The mechanisms controlling laminar flame anchoring on a cylindrical bluff-body are investigated using DNS and experiments. Two configurations are examined: water-cooled and uncooled steel cylinders. Comparisons between experimental measurements and DNS show good agreement for the flame root locations in the two configurations. In the cooled case, the flame holder is maintained at about $300 \mathrm{~K}$ and the flame is stabilized in the wake of the cylinder, in the recirculation zone formed by the products of combustion. In the uncooled case, the bluff-body reaches a steady temperature of about $700 \mathrm{~K}$ in both experiment and DNS and the flame is stabilized closer to it. The fully coupled DNS of the flame and the temperature field in the bluff-body also shows that capturing the correct radiative heat transfer from the bluff-body is a key ingredient to reproduce experimental results.
\end{abstract}

\section{Introduction}

The burnt gas temperatures reached in combustion chambers usually exceeds the maximum temperatures which can be sustained by most materials, especially metals used in engines. Therefore, cooling these walls as well as all chamber elements in contact with the flame is mandatory for combustion chamber designers. While cooling is obviously needed to preserve walls, its effects on the flames themselves has received less attention and is usually neglected in many CFD approaches. Flame/wall interaction, for example, is a field of combustion which has not been investigated yet with sufficient care [1-6]. In most cases, authors measure or compute the maximum wall heat fluxes induced by the flame but do not investigate the effects of the wall on the flame itself.

In the field of simulation, most models [7-11] assume adiabatic flows. For premixed flames, the famous BML (Bray Moss Libby) approach, for example, which is the workhorse of many theories for turbulent premixed flames $[12,13]$ assumes that a single variable (the progress variable $c$ ) is sufficient to describe the flow: this is true only when the flow is adiabatic. In the same way, many usual methods for chemistry tabulation such as FPV [14], FPI [15] or FGM

\footnotetext{
* Corresponding author.

E-mail address: mbrebion@imft.fr, miguel.brebion@gmail.com (M. Miguel-Brebion).
}

[16] assume that chemistry can be described using only two variables, the mixture fraction $z$ and the progress variable $c$, which implies that the flames must be adiabatic. ${ }^{1}$ Considering that wall heat fluxes in most chambers correspond to approximately $5-40 \%$ of the chamber total power, assuming adiabaticity is clearly not compatible with the high-precision methods which are sought today. Note that computing the interaction between the flame and the wall requires to compute both the flow and the temperature within the walls simultaneously: the LES code must be coupled with a heat transfer code within the combustor walls. This task is not simple $[19,20]$ because time scales are usually very different (a few milliseconds in the flow and a few minutes in the walls).

Among all walls present in a chamber, flame holders play a special role because they control the most sensitive zone of the chamber: the place where the flames are anchored. Any temperature change of the flame holder will induce a change of position for the flame roots and therefore a change in stability and efficiency. The coupling mechanisms between heat transfer within flameholder and flame stabilization have not been analyzed in detail yet. In a series of recent papers [21-23], the MIT group has numerically studied the stabilization of premixed flames on square

\footnotetext{
${ }^{1}$ Non adiabatic effects can be included in $(Z, c)$ tabulation as done by Marracino et al. [17] or Fiorina et al. [18] but this increases the complexity of the tabulation significantly.
} 


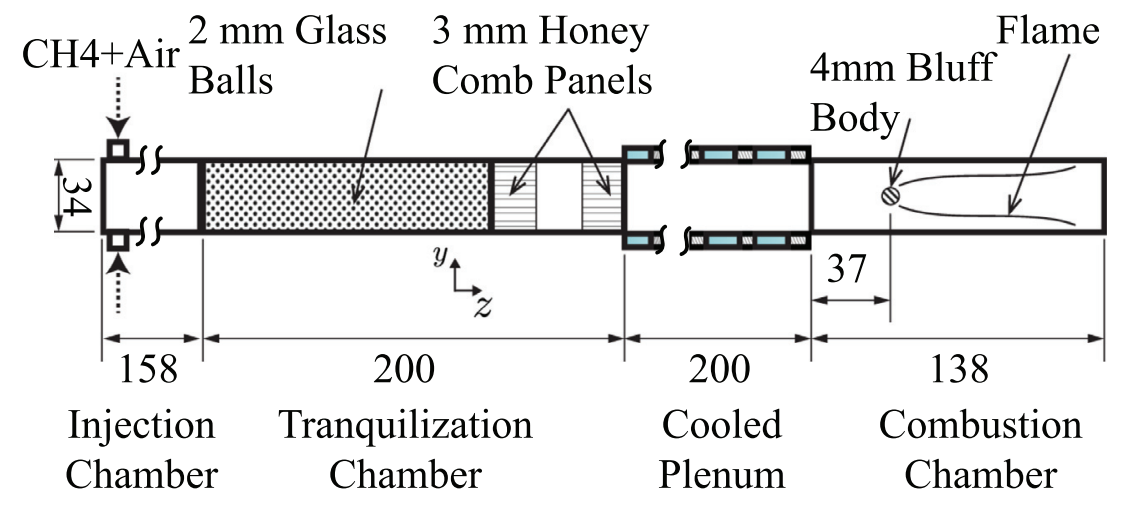

Fig. 1. Transverse cut of the burner.

flame holders and shown that the location of the flame roots but also the blow-off limits were strongly affected by the temperature of the flame holder.

The present study focuses on a similar question: which differences in flame anchoring are observed when the temperature of the flame holder varies from a low (typically $300 \mathrm{~K}$ ) to a high value $(700 \mathrm{~K})$. To obtain such a large variation in temperature, a premixed laminar methane/air flame is stabilized on a cylindrical flame holder. Two flame holders are used, with exactly the same external shape. The first one has an internal water cooling system, leading to a surface temperature close to $300 \mathrm{~K}$. The second one is a full, solid cylinder which is uncooled, leading to a surface temperature close to $700 \mathrm{~K}$.

Both experiments and DNS are used to analyze the differences in flame structure near the flame holder. Simulations are performed in dual mode: the flow is computed with DNS using a 13 species kinetic scheme for $\mathrm{CH}_{4} /$ air flames [24] while the temperature in the solid is computed with a heat transfer solver, coupled to the flow solver. The simulations, performed for cooled and uncooled flame holders, reveal drastic differences in flame root location and flow topologies. They also show that radiative heat transfer must be taken into account to predict the flame topology for the uncooled case.

Section 2 presents the experimental setup. The tools used for the coupled flow/solid simulation are described in Section 3. Results for the cooled flame holder are discussed in Section 4 before presenting the uncooled case in Section 5. Finally Section 6 discusses the influence of radiative heat fluxes on the flame stabilization when the flame holder is uncooled.

\section{Experimental configuration}

The experimental rig is shown in Fig. 1: a lean premixed methane-air V-flame is stabilized over steel cylindrical bluff body (radius of $r=4 \mathrm{~mm}$ ). The burner has a constant cross section of $h=34$ by $l=94 \mathrm{~mm}$ so that the flame remains two-dimensional. Individual mass flow meters are used to control air and methane flow rates. Fuel and oxidizer are premixed before entering the injection chamber though six holes. Glass wool, small glass balls and two honeycombs panels are used to laminarize the flow. The flow passes through a water-cooled plenum to ensure a constant fresh-gases temperature. Hot wire measurements downstream of the plenum show that the flow is laminar: the fluctuation level remains below $1 \%$ everywhere in the chamber. After the plenum, the flow enters the combustion chamber where the flame holder is located. Two different bluff-bodies have been used to stabilize the flame. The first one is a cooled steel cylinder (Fig. 2, left) maintained at $285 \mathrm{~K}$ by a $37 \mathrm{~g} \mathrm{~s}^{-1}$ mass flow rate of cooling water. The second flame holder is a solid steel cylinder, which has exactly the
Table 1

Operating conditions for the CBB and UBB cases.

\begin{tabular}{lll}
\hline Name & Quantity & Value \\
\hline$\Phi$ & Equivalence ratio & 0.75 \\
$u_{\mathrm{b}}$ & Bulk velocity & $1.07 \mathrm{~m} \mathrm{~s}^{-1}$ \\
$s_{\mathrm{I}}$ & Laminar flame speed & $0.24 \mathrm{~m} \mathrm{~s}^{-1}$ \\
$T_{\mathrm{u}}$ & Injection temperature & $292 \mathrm{~K}$ \\
$T_{\text {adia }}$ & Adiabatic flame temperature & $1920 \mathrm{~K}$ \\
\hline
\end{tabular}

same external geometry as the cooled one (Fig. 2, right). In the following, these cases will be denoted as CBB (Cooled Bluff-Body) and UBB (Uncooled Bluff-Body) respectively. Finally, the combustion chamber has a quartz window in the front, and one on each lateral side wall, for visualization.

The operating conditions are given in Table 1 . In these conditions, the flame is steady for all cases and the power of the burner is $7 \mathrm{~kW}$ for $\Phi=0.75$ and $u_{\mathrm{b}}=1.07 \mathrm{~m} \mathrm{~s}^{-1}$. In both cases, dimensionless flow parameters are identical. The Reynolds number based on the bluff-body diameter $R e_{\mathrm{bb}} \approx 520$ is low and the flow remains laminar. Without combustion, a Kármán vortex street is obtained at $f=40 \mathrm{~Hz}$ in the wake of the cylinder. For reacting mixtures, the flow becomes fully steady for all cases tested here. Similarly, the ratio between the laminar flame velocity and the bulk speed $s_{1} / u_{\mathrm{b}}$ $\approx 0.22$ is sufficiently low to avoid flashback events.

Flames are imaged on an intensified PCO-Sensicam camera equipped with a $\mathrm{CH}^{*}$ narrow band-pass filter and a $f / 16,180 \mathrm{~mm}$ telecentric lens [25] (Fig. 2).

In the UBB case, the full cylinder is attached at only one side of the combustion chamber. On the other side, there is a gap of approximately $3 \mathrm{~mm}$ between the cylinder and the quartz window. This gap drops to $1 \mathrm{~mm}$ at steady state because of thermal expansion. The flame holder temperature has been measured with a K-type thermocouple: $T_{\text {cyl }}^{\mathrm{UBB}}=670 \pm 40 \mathrm{~K}$. A temperature difference of about $70 \mathrm{~K}$ has been measured between the two extremities of the cylinder. This corresponds to a gradient of $\partial T / \partial x \approx 750 \mathrm{~K} \mathrm{~m}^{-1}$. The corresponding heat transfer is below $2 \mathrm{~W}$ so that axial heat flux is not taken into account in the DNS. This allows to run both the DNS and the heat transfer code on 2D meshes.

In the $\mathrm{CBB}$ case, the temperature elevation of the water used for cooling is equal to $\Delta T=0.15 \pm 0.05 \mathrm{~K}$ so that the cooling water temperature can be assumed to be constant. It leads to a total flux taken from the flame $\Phi_{\mathrm{s} \rightarrow \mathrm{w}}^{\mathrm{xp}}=\dot{m} C_{\mathrm{p}} \Delta T=24 \mathrm{~W}$.

The thermal properties of the steel used in both UBB and CBB cases are recalled in Table 2. The emissivity of the bluff body is directly linked to its surface state. In the present experiments, the bluff-bodies are oxidized so that an emissivity of $\epsilon=0.9$ is retained. The effects of $\epsilon$ are discussed using DNS in Section 6 . 

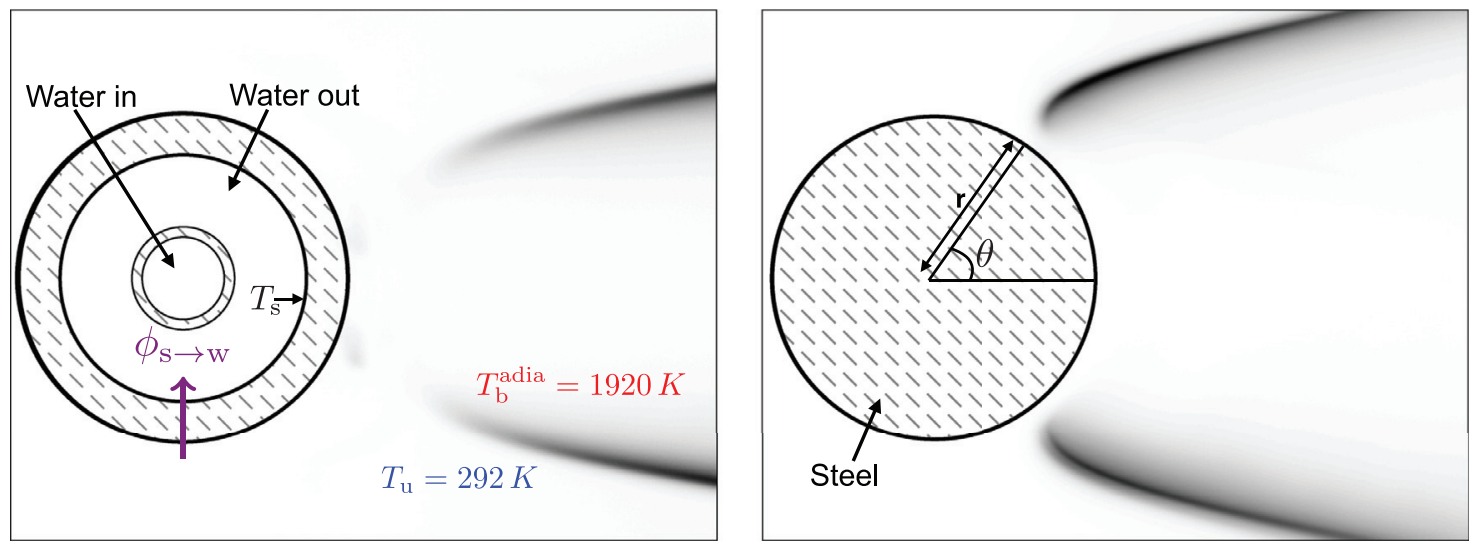

Fig. 2. Experimental fields of $\mathrm{CH}^{*}$ for $\mathrm{CBB}$ : cooled bluff-body (left) and UBB: uncooled bluff-body (right).

Table 2

Thermal properties of the steel used for the bluff-bodies. The emissivity $\epsilon$ ranges from 0.2 for polished surfaces to 0.9 for oxidized surfaces.

\begin{tabular}{llll}
\hline Material & $\rho c_{p}\left[\mathrm{~K}^{-1} \mathrm{~m}^{-3}\right]$ & $\lambda[\mathrm{W} / \mathrm{m} / \mathrm{K}]$ & $\epsilon$ \\
\hline $35 \mathrm{NCD} 16$ & $3.510^{6}$ & 32 & $0.2-0.9$ \\
\hline
\end{tabular}

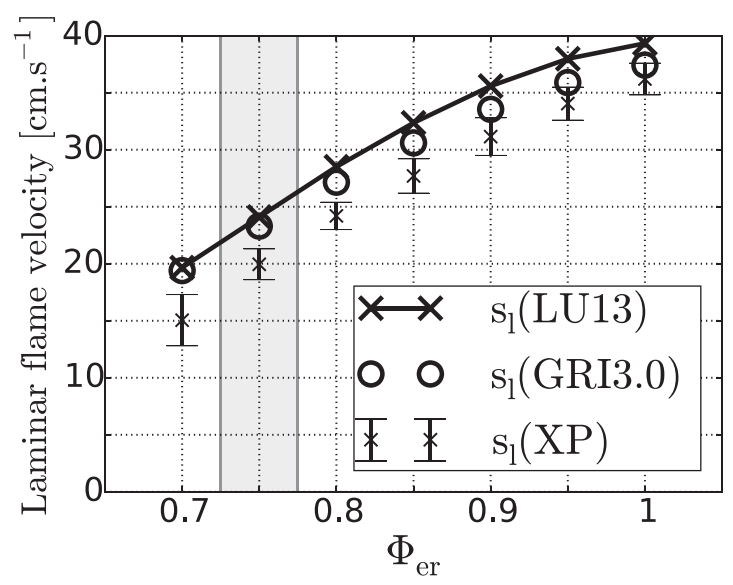

Fig. 3. Laminar flame speed comparison between the LU13 analytical mechanism, GRI-3.0 detailed mechanism and experimental results extracted from [31].

\section{Numerical strategy}

To capture the effects of flame holder cooling on the flame, a coupled DNS of the flow and of the temperature field within the flame holder is performed.

\subsection{Fluid and solid solver}

The Navier Stokes equations are solved with the AVBP solver using a third-order scheme for spatial differencing on a twodimensional hybrid mesh combined with an explicit two-step scheme for time advancement [26,27]. The NSCBC [13,28] formulation is used for the boundaries while the molecular transport is based on the Hirshfelder Curtis approximation [29].

A multistep analytical mechanisms, referred to as LU13 has been used to describe the chemical kinetics of the methane-air combustion [24]. Laminar flame velocities obtained with LU13 are shown in Fig. 3: $T=298 \mathrm{~K}$ and $P=101,300 \mathrm{~Pa}$. The LU13 scheme is compared with the detailed GRI-3.0 mechanism [30] but also with experimental results of Dirrenberger et al. [31]. The error bars in the experimental measurements correspond to the envelope of four different measurements performed by different authors. These measurements were realized using counter flow flames [32,33] or spherical flame [34]. The laminar flame velocity from the LU13 scheme is $4 \%$ higher than the one from the GRI-3.0 mechanism. However, a difference of about $15 \%$ is observed between the mean of the experimental measurement and the LU13 analytical mechanism at $\Phi=0.75$.

The resolution of the heat transfer equation in the bluff-body relies on an implicit [35] first-order forward Euler scheme for time integration and a second-order Galerkin scheme [36]. Local heat fluxes $\phi_{\mathrm{s}}$ are imposed in the solid solver at the boundary shared between the solid and the fluid domains. The solid solver then sends skin temperature back to the DNS code for the next iteration.

\subsection{Coupling strategy}

Both codes are coupled with a software called OpenPALM [37] which exchanges the thermal information at the external face of the bluff-body. The local temperature obtained by the solid solver on the cylinder surface solver is applied through an isothermal NSCBC boundary condition [28] in the fluid solver whereas the local heat flux is imposed in the solid solver. The characteristic flow time $\tau_{\mathrm{f}}$ is of the order of $50 \mathrm{~ms}$ while the solid characteristic time $\tau_{\mathrm{s}}$ is of the order of $10^{3} \mathrm{~s}$. The simulation of the flame for several $\tau_{\mathrm{s}}$ is impractical. The coupling strategy to accelerate the convergence towards steady state is that each domain (flow and solid) is advanced at its own characteristic time using a time step $\alpha_{\mathrm{f}} \tau_{\mathrm{f}}$ for the fluid and $\alpha_{\mathrm{s}} \tau_{\mathrm{s}}$ for the solid with $\alpha_{\mathrm{f}}=\alpha_{\mathrm{s}}$ [19]. This is equivalent to decreasing the heat capacity of the solid while preserving the conductivity.

Moreover, radiative heat losses from the flame holder must be accounted for when relatively high temperatures are reached. They are taken into account in the local flux condition imposed on in the solid solver by adding a radiative flux $\phi_{\text {rad }}$ :

$\phi_{\mathrm{rad}}=\sigma \epsilon\left(T^{4}-T_{\mathrm{ext}}^{4}\right)$

where $T$ is the local temperature at the cylinder surface. Radiation from the gas $\left(\mathrm{H}_{2} \mathrm{O}, \mathrm{CO}_{2}\right)$ and from the hot walls downstream of the combustion zone is neglected. Furthermore, walls at the same height of the flame holder are assumed to have a temperature close to the fresh gas and to behave as black bodies: $T_{\mathrm{ext}}=T_{\mathrm{u}}$.

\subsection{Meshing strategy}

An unstructured hybrid mesh is used to accurately capture the conjugate heat transfer between the solid and the reactive flow 

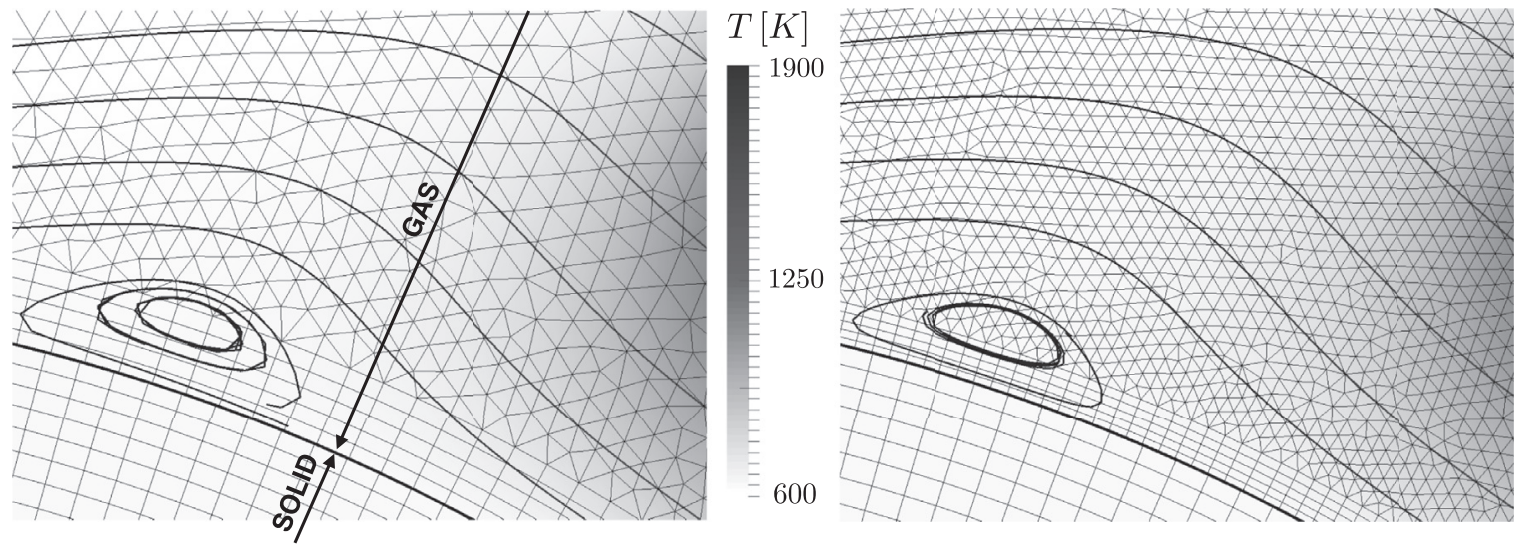

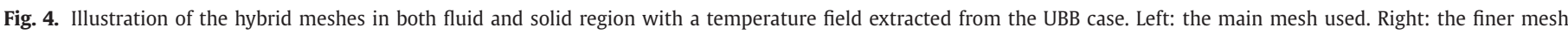
used for validation. Velocity streamlines are represented by solid thick lines.

$[38,39]$. Five layers of quad elements are used outside of the cylinder boundary (flow region) and ten are used inside (solid region). The remaining parts of the geometries are meshed with triangles (Fig. 4, left). The meshes for solid and fluid domains are not coincident on the flame holder skin and a second-order space interpolation is performed to transfer information between the two solvers.

A mesh resolution of $70 \mu \mathrm{m}$ is retained. First, it allows to correctly resolve the flame front. The flame thickness is defined by:

$\delta_{\text {th }}=\frac{T_{\text {adia }}-T_{\mathrm{u}}}{\max (d T / d x)}$

For a methane-air premixed flame at $\Phi=0.75$ and with $T_{\mathrm{u}}=$ $292 \mathrm{~K}: \delta_{\text {th }}=580 \mu \mathrm{m}$ so that at least 8 cells are obtained in the flame region. At this resolution, all transported species are accurately resolved across the flame front. The mesh size of $70 \mu \mathrm{m}$ also allows to capture both dynamic and thermal boundary layers along the cylinder. The thermal boundary layer thickness at the stagnation point is $L_{\mathrm{th}}=700 \mu \mathrm{m}$ and is thickened as the flow passes around the cylinder. It is meshed with at least 10 cells. The dynamic boundary layer is thicker than the thermal one (Prandtl number below unity). Finally, mesh independence was assessed by testing a finer mesh (Fig. 4, right), with a typical cell resolution of $40 \mu \mathrm{m}$, which resulted in negligible changes in the flame front position and velocity field. For instance, the small recirculation zone observed in the UBB case is identical on the two meshes.

\section{4. $C B B$ configuration}

Since the bluff-body temperature is controlled by a water flow which is not computed, a boundary condition at the inner diameter of the flame holder is required. The convective inner flux $\phi_{\mathrm{s} \rightarrow \mathrm{w}}$ (Fig. 2) is modeled through a Newton law at the solid/water boundary:

$\phi_{\mathrm{s} \rightarrow \mathrm{w}}=h_{\mathrm{turb}}\left(T_{\mathrm{s}}-T_{\mathrm{w}}\right)$

where $T_{\mathrm{S}}$ is the local inside skin temperature of the cylinder, $T_{\mathrm{W}}$ is the mean temperature of the cooling water in the outer passage and $h_{\text {turb }}$ is the heat transfer coefficient. The water flow is turbulent with a Reynolds number of $R e \approx 5800>R e_{\mathrm{c}} \approx 2400$ according to [40]. The heat transfer coefficient $h_{\text {turb }}$ for a turbulent flow in an annulus obtained by a correlation [41]:

$h_{\text {turb }}=c_{p} \rho v \frac{0.023}{\operatorname{Re}^{0.2} \operatorname{Pr}^{2 / 3}}, \operatorname{Pr}=\frac{\mu c_{p}}{\lambda_{1}}$

where $c_{p}$ and $\mu$ refers to the specific heat at constant pressure and the dynamic viscosity of the cooling water respectively and $v$ is the bulk velocity in the outer annulus. The corresponding turbulent heat transfer coefficient is $h_{\text {turb }} \approx 310^{4} \mathrm{~W} \mathrm{~m}^{-2} \mathrm{~K}^{-1}$.

Experimental and DNS results are compared by superposing iso-contours of the heat release rate (20\% of maximum) and $\mathrm{CH}^{*}$ field obtained in the experiments (Fig. 5, left). The location of the flame root is accurately reproduced in the DNS. Flame angles $(\Theta)$ from DNS and experiments are close to each other: $\Theta_{\text {DNS }}=$ $0.076 \pi \pm 0.006 \pi$ and $\Theta_{\mathrm{XP}}=0.067 \pi \pm 0.006 \pi$. This result is coherent with the differences in laminar flame velocity: Fig. 3 shows that LU13 overestimates experimental flame velocities by $10-15 \%$.

In this configuration, the flame roots are located $3 \mathrm{~mm}$ downstream of the bluff-body at the angle of $\theta_{\mathrm{CBB}} \approx 0.15 \pi$. Figure 5 , right shows the normalized heat flux entering the cylinder: $\phi_{\mathrm{r}}^{*}=$ $\vec{\phi}_{\text {fluid }} \cdot \vec{n} /\left(\rho_{u} Y_{\mathrm{CH}_{4}} s_{1} Q\right)$ where $\rho_{u}=1.2 \mathrm{~kg} \mathrm{~m}^{-3}$ and $Y_{\mathrm{CH}_{4}}=0.042$ are the gas density and methane mass fraction in the unburnt side respectively, $Q=50,100 \mathrm{Jg}^{-1}$ is the mass heat of reaction for methane/air combustion and $\vec{n}$ is the normal vector pointing inside of the cylinder. This flux is positive at all angles as the cylinder remains cooler than the unburnt mixture. It peaks at $\phi_{\mathrm{r}}^{*}=0.1$, a value comparable to maximum fluxes reached during SWQ (Side Wall Quenching) flame/wall interaction where reduced fluxes can reach 0.15 [13].

The flame root is located in the recirculation zone (Fig. 6) in the wake of the cylinder. Similar results were previously observed by Kedia et al [22] for a flame stabilized behind a square bluff-body in ceramic. The temperature is quasi uniform inside of the flame holder. It ranges between $285.15 \mathrm{~K}$, the temperature of the cooling water, up to $291 \mathrm{~K}$. The DNS data can be used to compute the total heat transfer between the cylinder and the cooling water:

$\Phi_{\mathrm{s} \rightarrow \mathrm{w}}=\int_{\theta} \phi_{r}\left(r_{\text {int }}\right) l r_{\text {int }} \mathrm{d} \theta$

where $r_{\mathrm{int}}=3 \mathrm{~mm}$ is the radius of the inner boundary of the cooled flame holder. This flux is equal to $31 \mathrm{~W}$ and is consistent with the experimental measurement based on the cooling water heating: $\Phi_{s \rightarrow \mathrm{w}}^{\exp }=24 \mathrm{~W}$.

The ratio between the heat losses along the cooled cylinder $(31 \mathrm{~W})$ and the total power of the burner $(7 \mathrm{~kW})$ shows that less than $0.5 \%$ of the thermal energy released by combustion is transferred to the cooled flame holder. The flame structure can be analysed by visualizing the maximum of the heat release rate along the flame front (Fig. 7).

This quantity has been normalized by the heat release rate of the equivalent laminar un-stretched adiabatic flame. Three different zones can be identified:

- The adiabatic zone $\left(A_{z}\right)$. Downstream of the cylinder $(z>$ $16 \mathrm{~mm}$ ), the heat release rate goes to unity showing that the 

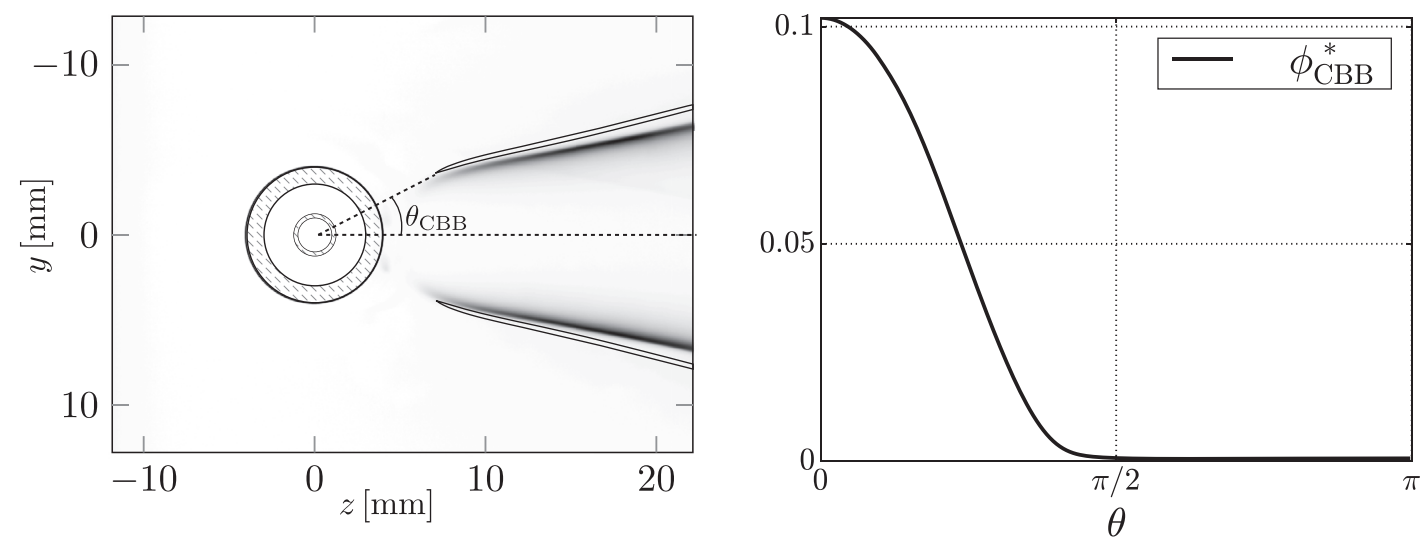

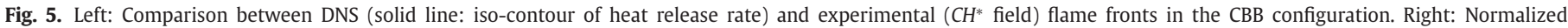
wall heat flux along the cooled cylinder external boundary.

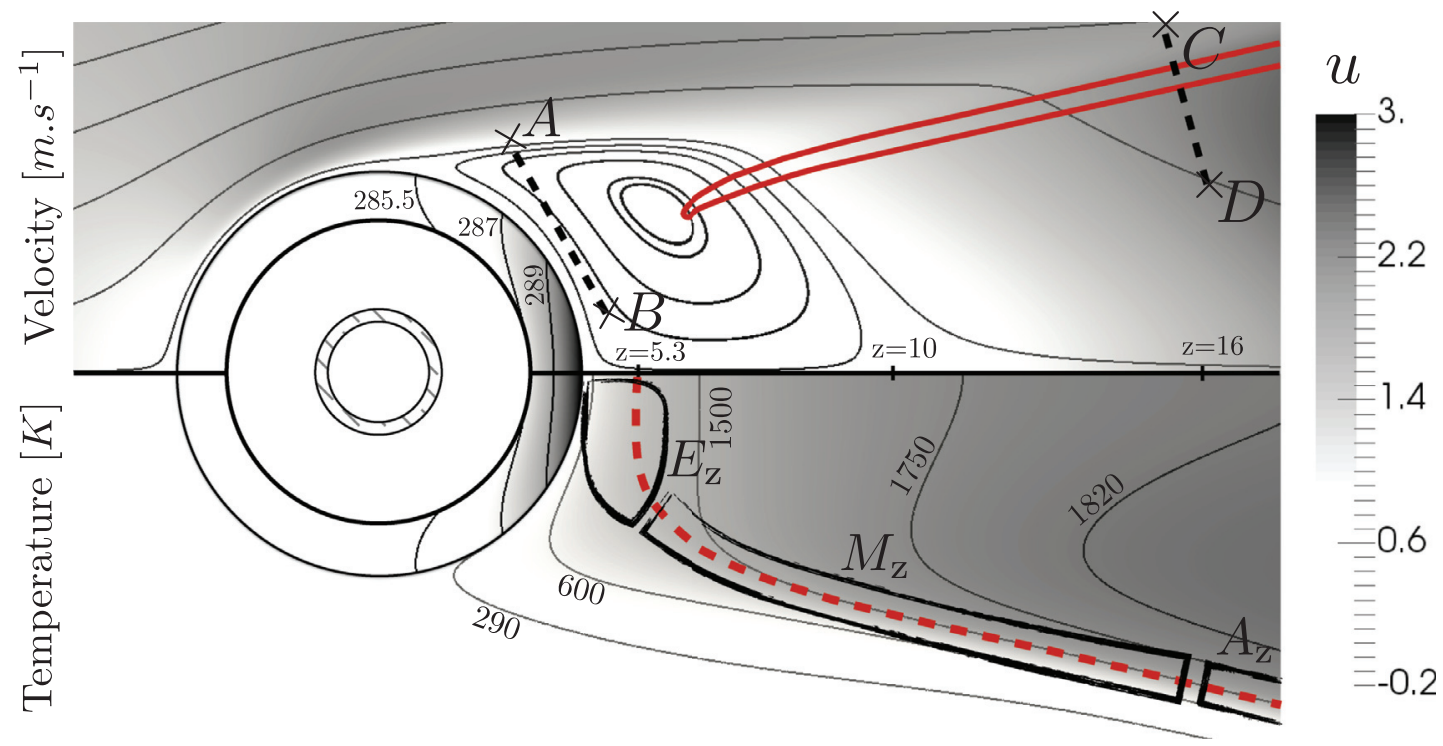

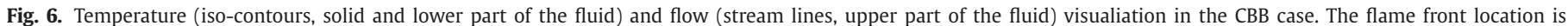
marked by the iso-contour of $20 \%$ of the maximum heat release in the upper part and by its centreline in the lower part.

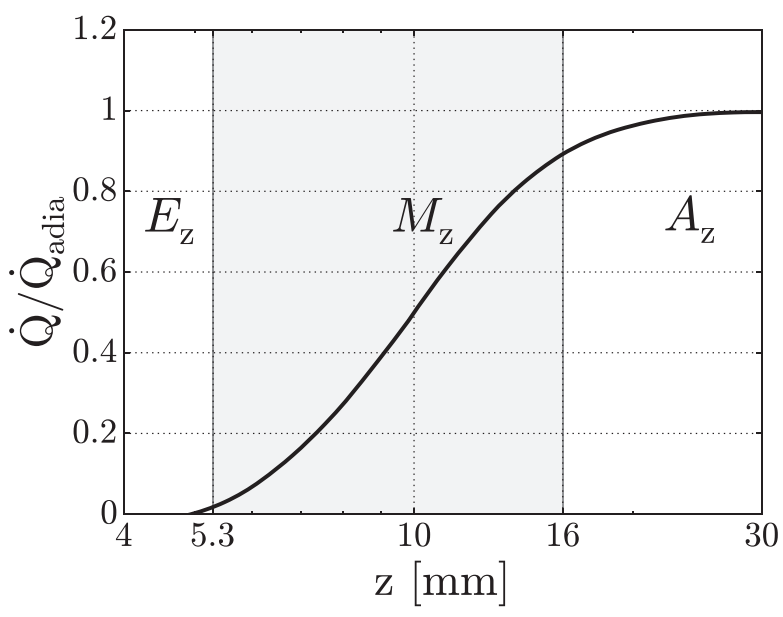

Fig. 7. Normalized maximum heat release rate along the flame front (dashed line in Fig. 6) for the CBB case. $z=4 \mathrm{~mm}$ corresponds to the cylinder end.

flame has forgotten its stabilization zone and is not affected by the cooled flame holder. Typical profiles of mass fractions of one reactant $\left(\mathrm{CH}_{4}\right)$, one product $\left(\mathrm{H}_{2} \mathrm{O}\right)$ and one reaction inter- mediate $\left(\mathrm{CH}_{3}\right)$ are displayed in Fig. 8 along the path $[\mathrm{CD}]$ of Fig. 6.

- The extinction zone $\left(E_{z}\right)$. Close to the bluff-body $(z<5.3 \mathrm{~mm})$, the flame is quenched. In this region (path $[A B]$ in Fig. 6), the flow is dominated by diffusion processes since no production nor consumption of reaction intermediates is observed. The reactants present away from the wake of the cylinder (point $A$, Fig. 6) are mixed with the products of combustion convected in the recirculation zone (point $B$ ).

- The mixed zone $\left(M_{z}\right)$. This zone is located downstream of the center of the recirculation zone $(z \in[5.3,16] \mathrm{mm})$. Here, the combustion is less intensive because the fresh mixture has been mixed with products of combustion so that the local equivalence ratio is decreased. This is the zone where the flame roots are located. Figure 7 shows that the transition from the quenched state (zone $E_{z}$ ) to the fully burning state (zone $A_{z}$ ) is progressive in the zone $M_{z}$ and takes place over a length of approximately $1 \mathrm{~cm}$.

\section{UBB configuration}

For the uncooled flame holder, a steady symmetrical flame is also observed. The comparison between DNS and experiments is very good (Fig. 9, left). Compared to the CBB case (Fig. 5, left), 


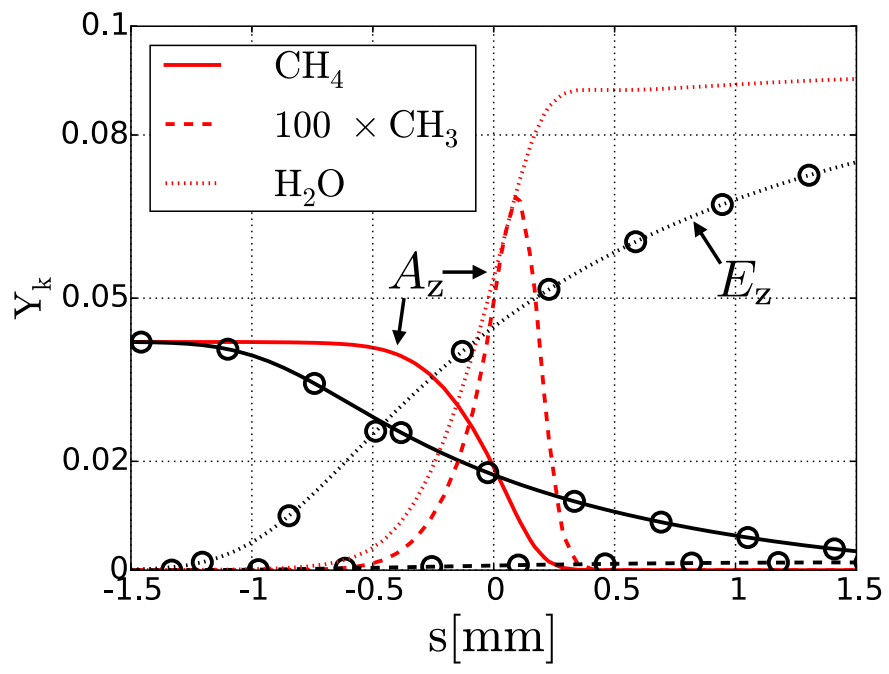

Fig. 8. Mass fractions of $\mathrm{CH}_{4}, \mathrm{CH}_{3}$ and $\mathrm{H}_{2} \mathrm{O}$ along the paths $[A B] \in E_{z}$ (curve with markers) and $[C D] \in A_{z}$ (curves). The mass fraction of $\mathrm{CH}_{3}$ is multiplied by a factor 100.

the flame is much closer to the flame holder. The radial heat flux in the fluid region can be used to determine its angle. The angle $\theta_{\mathrm{UBB}}$ corresponds to the azimuthal point where the heqt flux changes sign: $\theta_{\mathrm{UBB}}=\theta / \vec{\phi}_{\text {fluid }} \cdot \vec{n}=0$ where $\vec{n}$ is the normal unit vector pointing inside of the cylinder. As shown in Fig. 9, right: $\theta_{\mathrm{UBB}}=0.4 \pi$. Furthermore, the flame roots are located at $0.3 \mathrm{~mm}$ of the flame holder.

Temperature and velocity fields obtained in DNS for both solid and fluid zones are displayed in Fig. 10. Color scales used to visualize the temperature fields have been separately adapted for both regions. At steady state, the mean temperature of the bluffbody is closed to $700 \mathrm{~K}$ with a minimum of $696 \mathrm{~K}$ at the stagnation point and a maximum of $711 \mathrm{~K}$ at the trailing edge. This result is consistent with experimental measurements of $670 \pm 40 \mathrm{~K}$ realized with a thermocouple just after stopping the flame. Close to the cylinder, the temperature field in the fluid region indicates that the fresh gases are heated by the hot cylinder on the upstream side. Two small recirculation zones are observed. The first one $\left(R Z_{1}\right)$ is located upstream of the flame front, where the laminar unburnt flow separates. Its temperature is very close to the one of the bluff-body. The second one $\left(R Z_{2}\right)$ is located behind the wake of the cylinder but it is much smaller than it was for the $\mathrm{CBB}$ case (Fig. 6) due to the flow expansion. Contrary to the CBB case,

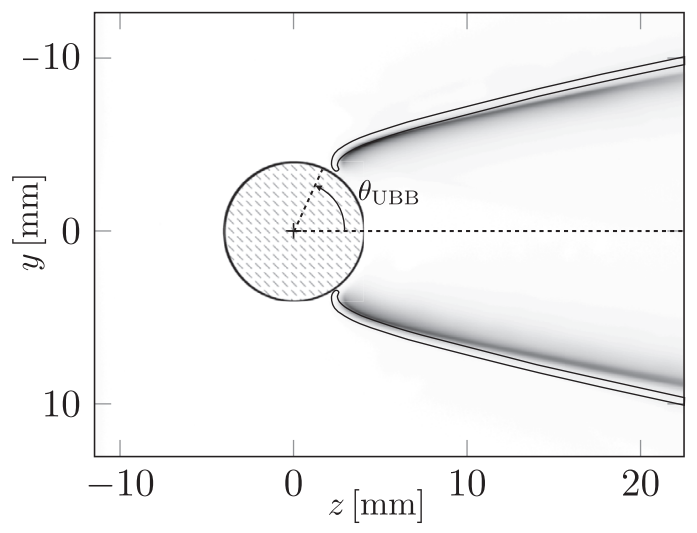

the flame roots are located ustream of the back recirculation zone $\left(R Z_{2}\right)$ showing that this stabilization follows different mechanisms.

The DNS data can be used to establish an energy balance for the uncooled flame holder. To do this, it is useful to separate the skin of the bluff-body into two zones: upstream $(\theta>0.4 \pi$ in Fig. 9), a large part of the bluff-body is cooled by the incoming gases, taking a flux $\Phi_{S} \rightarrow$ g away from it:

$\Phi_{\mathrm{s} \rightarrow \mathrm{g}}=\int_{\phi_{\mathrm{r}}<0} \phi_{r} \operatorname{lr} \mathrm{d} \theta$

where $\phi_{r}=\vec{\phi}_{\text {fluid }} \cdot \vec{n}$ is the radial heat flux in the fluid region taken at the boundary of the bluff-body and $\vec{n}$ is the normal unit vector pointing inside of the cylinder. Downstream of the bluff body $(\theta<$ $0.4 \pi)$, the burnt gases heat up the cylinder, injecting a flux $\Phi_{\mathrm{g} \rightarrow \mathrm{s}}$ :

$\Phi_{\mathrm{g} \rightarrow \mathrm{s}}=\int_{\phi_{\mathrm{r}}<0} \phi_{r} \operatorname{lr} \mathrm{d} \theta$

The separation of the two zones is simply obtained from the sign of the local heat flux. The radiative flux lost by the cylinder $\Phi_{\text {rad }}$ is:

$\Phi_{\text {rad }}=-\oint \epsilon \sigma\left(T^{4}-T_{\text {ext }}^{4}\right) \operatorname{lrd} \theta$

DNS results show that $\Phi_{\mathrm{g} \rightarrow \mathrm{s}}=66.5 \mathrm{~W}$ while $\Phi_{\mathrm{s} \rightarrow \mathrm{g}}=-36.9 \mathrm{~W}$ and $\Phi_{\text {rad }}=-29.5 \mathrm{~W}$ so that the global budget is closed: $\Phi_{\mathrm{g} \rightarrow \mathrm{s}}+$ $\Phi_{\mathrm{s} \rightarrow \mathrm{g}}+\Phi_{\mathrm{rad}}=0$. The input heat transfer $\Phi_{\mathrm{g} \rightarrow \mathrm{s}}$ is larger than it is for the CBB case (31 W) due to the vicinity of the flame. Figure 11 shows the flux line inside the bluff-body. One can see that heat coming from the burnt gases is participating to the heating up of the fresh gases. Similarly to the CBB case, three zones can be identified for the flame front structure (Fig. 12):

- The adiabatic zone $\left(A_{z}\right)$. Here, the fresh reactants have not been heated by the hot bluff-body or diluted by burnt gases. As a consequence, an adiabatic, almost un-stretched laminar flame is observed and the heat release rate values are similar to the equivalent one-dimensional adiabatic flame. The adiabatic zones encountered in both the UBB and the CBB cases are similar in terms of flame dynamics.

- The over-reactive zone $\left(\mathrm{O}_{z}\right)$. Here, the flame is more intense than the corresponding un-stretched adiabatic flame. The excess in burning rate is about $25 \%$ since the unburnt mixture is heated by the hot cylinder (Fig. 11). This increases the burning rate by accelerating kinetics: the peak mass fraction of $\mathrm{CH}_{3}$ is $20 \%$ greater than in the adiabatic zone as shown in Fig. 13 on the path $[G H]$.

- The quenching zone $\left(Q_{z}\right)$. Close to the bluff-body, the flame is quenched due to the conjugate heat transfer from the fluid to

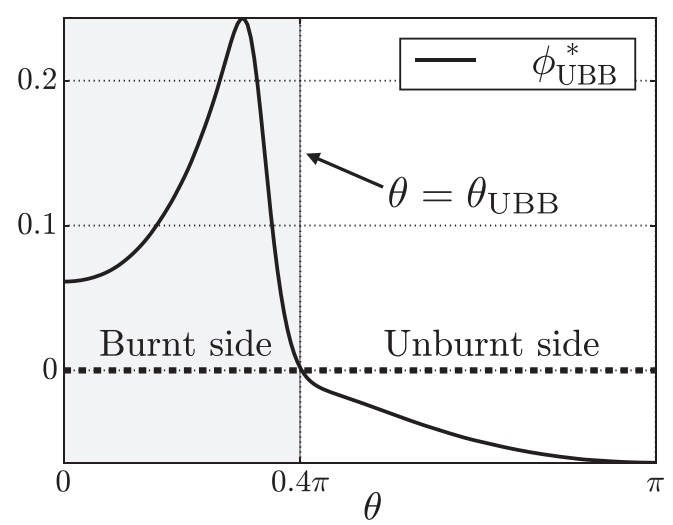

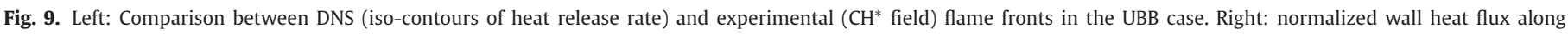
the uncooled cylinder. 


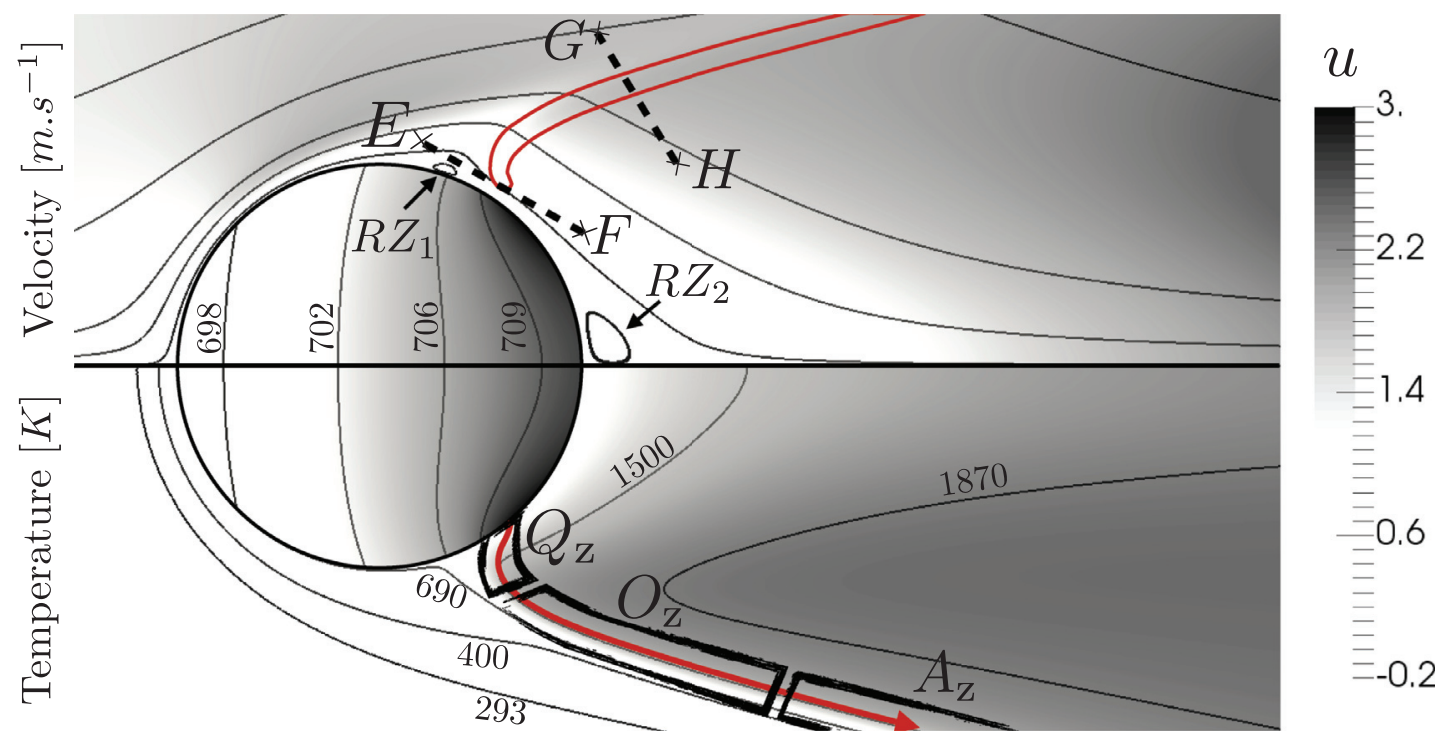

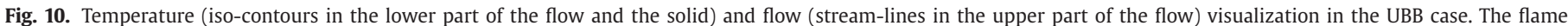
front location is recalled by the iso-contour of $20 \%$ of the maximum heat release and by its centerline.

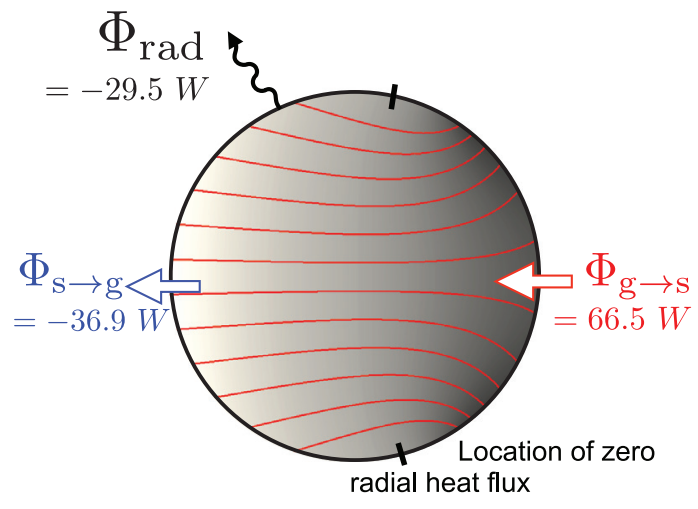

Fig. 11. Thermal budget of the uncooled cylinder (all fluxes are counted positive when entering the cylinder). Flux lines are represented inside of the cylinder.

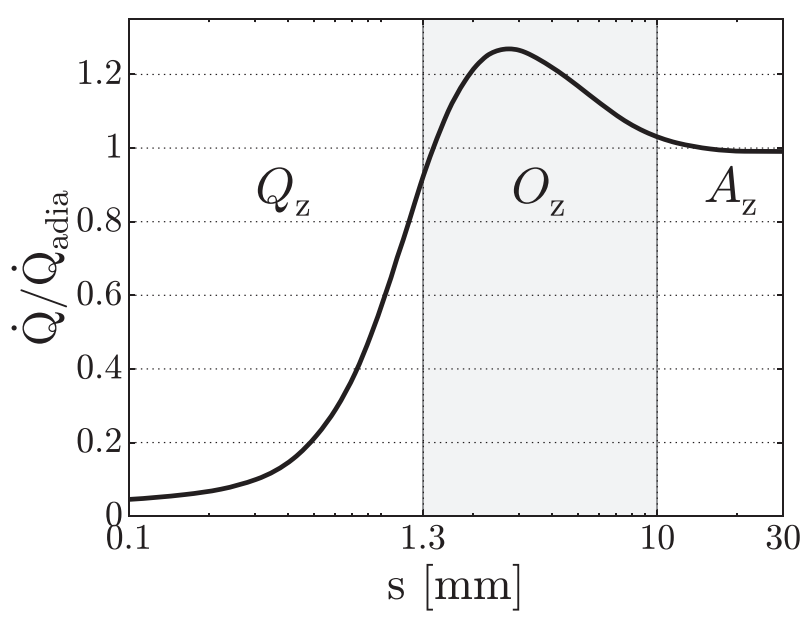

Fig. 12. Normalized maximum heat release rate along the flame front centreline (curvilinear abscissae). Three regions of interest are denoted: the quenching zone $\left(Q_{z}\right)$, the over-reactive zone $\left(O_{z}\right)$ and the adiabatic zone $\left(A_{z}\right)$.

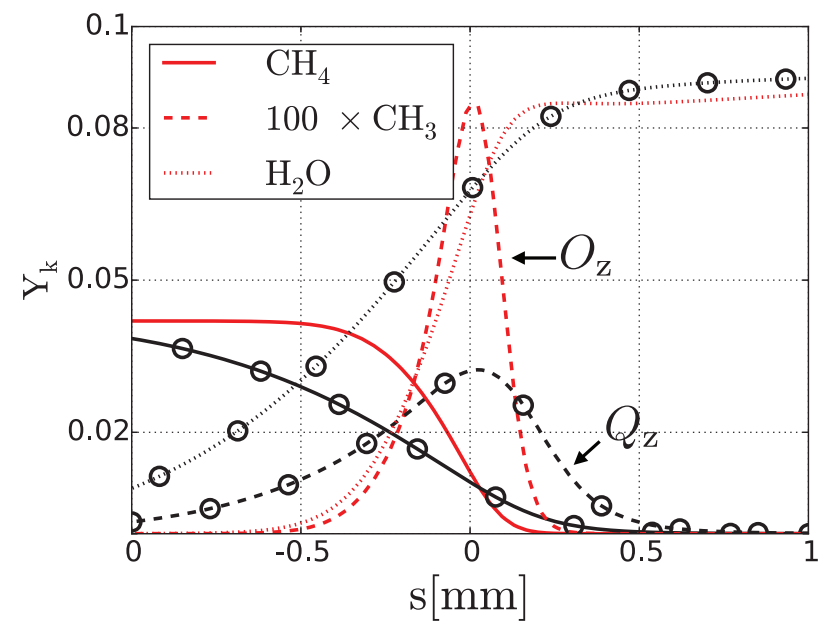

Fig. 13. Mass fractions of $\mathrm{CH}_{4}, \mathrm{CH}_{3}$ and $\mathrm{H}_{2} \mathrm{O}$ along the paths $[E F] \in \mathrm{Q}_{z}$ (curves with markers) and $[\mathrm{GH}] \in \mathrm{O}_{\mathrm{z}}$ (curves) plotted against their normalized curvilinear abscissae in the UBB case. the bluff-body. This region may be compared with the academical flame/wall interaction zone discussed in both experimental and theoretical studies by Von Kármán et al. [42], Lu et al. [1] and more recently by Buckmaster [43] and Vedarajan and Buckmaster [44], who introduced the concept of edge flame. Flame/wall interaction has also been investigated numerically in Head On or Side Wall quenching configurations $[4,45]$ and more recently in a turbulent channel $[5,46]$. The mass fraction profiles of $\mathrm{CH}_{4}, \mathrm{CH}_{3}$ and $\mathrm{H}_{2} \mathrm{O}$ are displayed in Fig. 13 along the path $[E F]$, described in Fig. 12. The presence of the reaction intermediate $\mathrm{CH}_{3}$ proves that chemical reactions are still occurring close to the cylinder. Furthermore, the flame front is thicker in the quenching zone than the adiabatic or the over reactive zones. This is due to thermal losses which slow kinetics down. Finally, the normalized heat flux between the fluid and the solid $\phi_{\mathrm{r}}^{*}$ is shown in Fig. 9, right, along the cylinder. It reaches a maximum of 0.24 , which is coherent with values obtained during stagnation quenching events on a cold wall: $\phi_{\mathrm{SQ}}^{*} \approx 0.33$ [47]. It is also much higher than it was for the CBB case $\phi_{\mathrm{r}}^{*}=0.1$ (Fig. 5). 


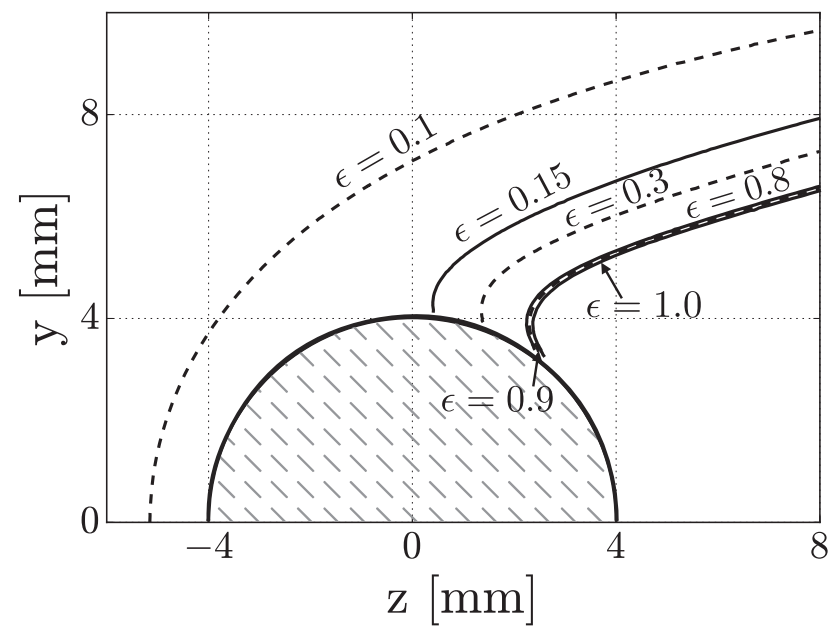

Fig. 14. Flame shapes for emissivity ranging from $\epsilon_{\min }=0.1$ to $\epsilon_{\max }=1$.

\section{Influence of the cylinder emissivity}

Section 5 showed that radiative heat transfer represents $45 \%$ of the bluff-body heat losses for the UBB case. This suggests that changes in stabilization mechanisms may be induced by changing the flame holder emissivity and its temperature. Different computations have been carried out with emissivity ranging between 0.02 and 1.

DNS results show that the flame root position (Fig. 14) is roughly independent of the emissivity between $\epsilon=0.8$ (weakly oxidized bluff-body) and $\epsilon=1.0$ (perfect black body). The corresponding averaged temperatures of the bluff-body computed in the DNS are $T_{\epsilon=0.8}=724 \mathrm{~K}, T_{\epsilon=0.9}=705 \mathrm{~K}$ and $T_{\epsilon=1.0}=693 \mathrm{~K}$. All these results are contained within the upper bound of the confidence interval of the experimental measurement of the uncooled bluffbody temperature.

Once the emissivity of the flame holder decreases below $\epsilon=$ 0.8 , the flame roots move upstream. For a low emissivity $(\epsilon=$ $0.15)$, the flame is stabilized at $\theta_{\epsilon=0.15} \approx \pi / 2$. In this case, half of the bluff-body is immersed in the burnt gases and its mean temperature increases to $T_{\epsilon=0.15}=1075 \mathrm{~K}$. A dramatic change occurs when the emissivity goes below 0.15: the flame jumps ahead of the cylinder. In this case, the temperature of the bluff-body, which is completely immersed in the burnt gases ranges between 1500 and $1900 \mathrm{~K}$, depending on the emissivity. Flame root angles and the corresponding normalized mean cylinder temperature are displayed in Fig. 15 for $\epsilon \in[0.02,1]$. The temperature of the cylinder increases with the flame root angle as the cylinder is surrounded by more burnt gases. When the flame is "upstream stabilized", the bluff-body mean temperature can be predicted by a simple model by assuming a uniform temperature in the cylinder: $T_{\text {cyl }}$. Using a constant heat transfer coefficient measured in the DNS: $h \approx$ $100 \mathrm{~W} \mathrm{~m}^{-2} \mathrm{~K}^{-1}$ and neglecting the radiative fluxes absorbed by the hot cylinder:

$\sigma \epsilon T_{\text {cyl }}^{4}+h\left(T_{\text {cyl }}-T_{\text {adia }}\right)=0$

The temperature $T_{\text {cyl }}$ of the cylinder is solution of the fourth order polynomial in Eq. (6.1). In the limit where $\epsilon<0.1$, the temperature of the cylinder remains close to the adiabatic flame temperature. A Taylor expansion of $\left(T_{\text {adia }}-T_{\text {cyl }}\right) / T_{\text {adia }}$ provides :

$\frac{T_{\text {adia }}-T_{\text {cyl }}}{T_{\text {adia }}} \approx \frac{1 / 4}{1+h /\left(4 \sigma \epsilon T_{\text {adia }}^{3}\right)}$

According to Eq. (6.2), an increase of the emissivity decreases the cylinder temperature as expected. Mean temperatures in the UBB

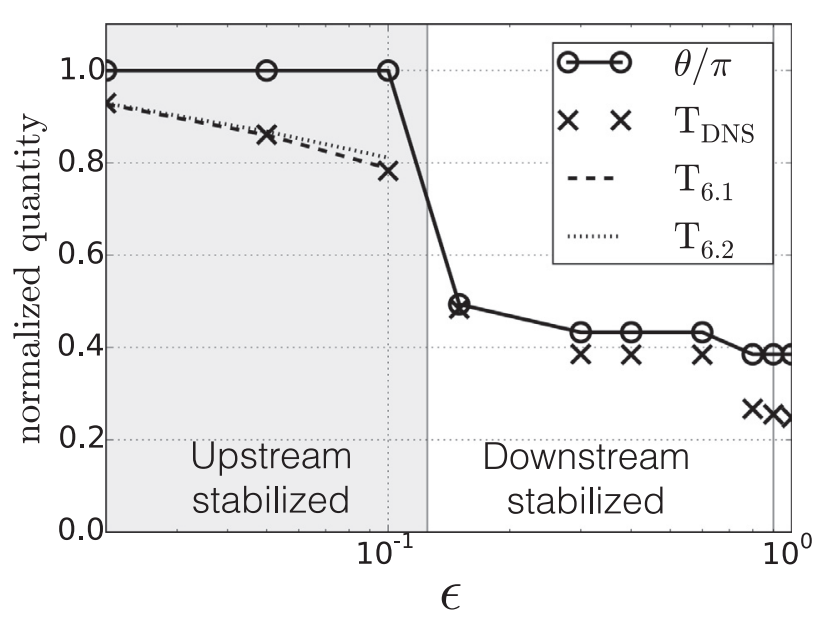

Fig. 15. Flame root angle $\theta$ and normalized temperature $\left(T-T_{\mathrm{u}}\right) /\left(T_{\mathrm{adia}}-T_{\mathrm{u}}\right)$ for cylinder emissivity between 0.02 and 1 . The temperature predicted by the model 6.1 and its approximation 6.2 are also displayed when the flame is stabilized upstream.

case for the DNS, the model of Eq. (6.1) and its approximation (6.2) are displayed in Fig. 15 where $\epsilon$ goes from 0.002 to 1 . This figure confirms the topology discontinuity at $\epsilon=0.15$ and shows that the simple Eq. (6.2) is sufficient to predict the variations of the flame holder temperature with $\epsilon$ when the flame is stabilized upstream of the flame holder.

\section{Conclusions}

A comparison between DNS and experiments has been carried out to study the anchoring mechanism of a flame attached on a cylindrical bluff-body. Two distinct configurations have been scrutinized. In the cooled bluff-body case (CBB) the flame holder temperature is about $300 \mathrm{~K}$ and the flame is stabilized approximately one radius downstream of the cylinder at an angle $\theta_{\mathrm{CBB}} \approx$ $0.15 \pi$ and attached at the center of the recirculation zone in which products and reactants are mixed. In the uncooled bluff-body case (UBB), the temperature reaches $700 \mathrm{~K}$ and the flame is attached closer to the cylinder at $\theta_{\mathrm{UBB}} \approx 0.4 \pi$. A good agreement between DNS and experiments is obtained for the shape for both cases. Finally, it has been shown that this temperature is controlled by the equilibrium of the convective and radiative heat fluxes occurring along the bluff body: the emissivity of the flame holder can change the flame stabilization location (upstream or downstream of the flame holder). A change of emissivity (a decrease) can lead to a flame jumping upstream of the flame holder and its destruction. More generally, these results show that the temperature of flame holders has a major effect on the flame topology and must be included in simulations as an important parameter.

\section{Aknowledgments}

This work was granted access to the high-performance computing resources of CINES under the allocation x20152b7036 made by Grand Equipement National de Calcul Intensif. The research leading to these results has received funding from the European Research Council under the European Union's Seventh Framework Programme (FP/2007-2013) / ERC Grant agreement ERC-AdG 319067-INTECOCIS. The authors also thank A. Felden, who implemented the LU13 scheme in the flow solver and Dr. A. Ghani for his helpful comments concerning laminar flame velocities. 


\section{References}

[1] J.H. Lu, O. Ezekoye, R. Greif, F. Sawyer, Unsteady heat transfer during side wall quenching of a laminar flame, Symp. (Int.) Combust. 31 (1) (1990) 441-446.

[2] G. Bruneaux, T. Poinsot, J.H. Ferziger, Premixed flame-wall interaction in a turbulent channel flow: budget for the flame surface density evolution equation and modelling, J. Fluid Mech. 349 (1997) 191-219.

[3] G. Bruneaux, K. Akselvoll, T. Poinsot, J. Ferziger, Flame-wall interaction in a turbulent channel flow, Combust. Flame 107 (1/2) (1996) 27-44.

[4] I.S. Wichman, G. Bruneaux, Head-on quenching of a premixed flame by a cold wall, Combust. Flame 103 (4) (1995) 296-310.

[5] A. Gruber, R. Sankaran, E.R. Hawkes, J.H. Chen, Turbulent flame wall interaction: a direct numerical simulation study, J. Fluid Mech. 658 (2010) 5-32.

[6] D. Mejia, L. Selle, R. Bazile, T. Poinsot, Wall-temperature effects on flame response to acoustic oscillations, Proc. Combust. Inst. 35 (3201-3208) (2015) 3.

[7] K. Mahesh, G. Constantinescu, S. Apte, G. Iaccarino, F. Ham, P. Moin, Large eddy simulation of reacting turbulent flows in complex geometries, ASME J. Appl. Mech. 73 (2006) 374-381.

[8] P. Schmitt, T. Poinsot, B. Schuermans, K.P. Geigle, Large-eddy simulation and experimental study of heat transfer, nitric oxide emissions and combustion instability in a swirled turbulent high-pressure burner, J. Fluid Mech. 570 (2007) $17-46$.

[9] G. Staffelbach, L. Gicquel, G. Boudier, T. Poinsot, Large eddy simulation of self-excited azimuthal modes in annular combustors, Proc. Combust. Inst. 32 (2009) 2909-2916.

[10] P. Wolf, G. Staffelbach, A. Roux, L. Gicquel, T. Poinsot, V. Moureau, Massively parallel LES of azimuthal thermo-acoustic instabilities in annular gas turbines, C. R. Acad. Sci. Méc. 337 (6-7) (2009) 385-394.

[11] A. Ghani, T. Poinsot, L. Gicquel, G. Staffelbach, Les of longitudinal and transverse self-excited combustion instabilities in a bluff-body stabilized turbulent premixed flame, Combust. Flame 162 (11) (2015) 4075-4083.

[12] K.N.C. Bray, Turbulent flows with premixed reactants in turbulent reacting flows, Topics in applied physics, vol. 44, Springer Verlag, New York, 1980.

[13] T. Poinsot, D. Veynante, Theoretical and numerical combustion, third ed., RT Edwards, Inc., 2011. www.cerfacs.fr/elearning.

[14] C.D. Pierce, P. Moin, Progress-variable approach for large eddy simulation of non-premixed turbulent combustion, J. Fluid Mech. 504 (2004) 73-97.

[15] B. Fiorina, O. Gicquel, D. Veynante, Turbulent flame simulation taking advantage of tabulated chemistry self-similar properties, Proc. Combust. Inst. 32 (2009) 1687-1694.

[16] G. Kuenne, A. Ketelheun, J. Janicka, LES modeling of premixed combustion using a thickened flame approach coupled with FGM tabulated chemistry, Combust. Flame 158 (9) (2011) 1750-1767.

[17] B. Marracino, D. Lentini, Radiation modelling in non-luminous nonpremixed turbulent flames, Combust. Sci. Technol. 128 (1-6) (1997) 23-48.

[18] B. Fiorina, R. Baron, O. Gicquel, D. Thevenin, S. Carpentier, N. Darabiha, Modelling non-adiabatic partially premixed flames using flame-prolongation of ILDM, Combust. Theory Model. 7 (3) (2003) 449-470.

[19] F. Duchaine, S. Mendez, F. Nicoud, a. Corpron, V. Moureau, T. Poinsot, Conjugate heat transfer with large eddy simulation for gas turbine components, $C$. R. Méc. 7 (6-7) (2009) 550-561.

[20] S. Berger, S. Richard, G. Staffelbach, F. Duchaine, L. Gicquel, Aerothermal prediction of an aeronautical combustion chamber based on the coupling of large eddy simulation, solid conduction and radiation solvers, ASME Turbo Expo 2015: Turbine Technical Conference and Exposition, American Society of Mechanical Engineers (2015).

[21] K.S. Kedia, C. Safta, J. Ray, H.N. Najm, A.F. Ghoniem, A second-order coupled immersed boundary-SAMR construction for chemically reacting flow over a heat-conducting Cartesian grid-conforming solid, J. Comput. Phys. 272 (2014) 408-428.
[22] K.S. Kedia, A.F. Ghoniem, The anchoring mechanism of a bluff-body stabilized laminar premixed flame, Combust. Flame 161 (9) (2014) 2327-2339.

[23] K.S. Kedia, A.F. Ghoniem, The response of a harmonically forced premixed flame stabilized on a heat-conducting bluff-body, Proc. Combust. Inst. 35 (1) (2014) 1065-1072.

[24] R. Sankaran, E.R. Hawkes, J.H. Chen, T. Lu, C.K. Law, Structure of a spatially developing turbulent lean methane-air bunsen flame, Proc. Combust. Inst. 31 I (2007) 1291-1298.

[25] R.B. Price, I.R. Hurle, T.M. Sugden, Optical studies of the generation of noise in turbulent flames, Symp. (Int.) Combust. 12 (1) (1969) 1093-1102.

[26] O. Colin, M. Rudgyard, Development of high-order Taylor Galerkin schemes for LES, J. Comput. Phys. 162 (2) (2000) 338-371.

[27] V. Moureau, G. Lartigue, Y. Sommerer, C. Angelberger, O. Colin, T. Poinsot, Numerical methods for unsteady compressible multi-component reacting flows on fixed and moving grids, J. Comput. Phys. 202 (2) (2005) 710-736.

[28] T. Poinsot, S. Lele, Boundary conditions for direct simulations of compressible viscous flows, J. Comput. Phys. 99 (2) (1992) 352.

[29] J.O. Hirschfelder, C.F. Curtiss, R.B. Bird, M.G. Mayer, Molecular theory of gases and liquids, vol. 26, Wiley, New York, 1954.

[30] G.P. Smith, D.M. Golden, M. Frenklach, N.W. Moriarty, B. Eiteneer, M. Goldenberg, C.T. Bowman, R.K. Hanson, S. Song, W.C. Gardiner Jr, et al., Gri 3.0 mechanism, Gas Research Institute, 1999. http://www.me.berkeley.edu/gri_mech.

[31] P. Dirrenberger, H. Le Gall, R. Bounaceur, O. Herbinet, P.A. Glaude, A. Konnov, F. Battin-Leclerc, Measurements of laminar flame velocity for components of natural gas, Energy Fuel 25 (9) (2011) 3875-3884.

[32] M.I. Hassan, K.T. Aung, G.M. Faeth, Measured and predicted properties of laminar premixed methane/air flames at various pressures, Combust. Flame 115 (4) (1998) 539-550.

[33] C.M. Vagelopoulos, F.N. Egolfopoulos, Direct experimental determination of laminar flame speeds, Symp. (Int.) Combust. 27 (1) (1998) 513-519.

[34] I. Dyakov, A.A. Konov, J.D. Ruyck, K.J. Bosschaart, E.C.M. Brock, L.P.H. De Goey, Measurement of adiabatic burning velocity in methane-oxygen-nitrogen mixtures, Combust. Sci. Technol. 172 (1) (2001) 81-96.

[35] V.A.L. Erie, V. Frayssé, L. Giraud, S. Gratton, A set of GMRES routines for real and complex arithmetics on high performance computers, ACM Trans. 31 (2) (2005) 228-238.

[36] J. Donea, A. Huerta, Finite element methods for flow problems, John Wiley \& Sons, 2003.

[37] S. Buis, A. Piacentini, D. Déclat, the PALM Group, PALM: a computational framework for assembling high-performance computing applications, Concur. Comput. - Pract. Exp. 18 (May 2004) (2006) 231-245.

[38] M.-P. Errera, F. Duchaine, Comparative study of coupling coefficients in Dirichlet Robin procedure for fluid-structure aero thermal simulations, J. Comput. Phys. 312 (February) (2016) 218-234.

[39] M. Boileau, F. Duchaine, J.C. Jouhaud, Y. Sommerer, Large-eddy simulation of heat transfer around a square cylinder using unstructured grids, AIAA J. 51 (2) (2013) 372-385.

[40] H.S. Dou, B.C. Khoo, H.M. Tsai, Critical condition for flow transition in a fulldeveloped annulus flow, J. Pet. Sci. Eng. 71 (2000) 1-6.

[41] W.H. MacAdams, Heat transmission, McGraw-Hill, New York, 1954

[42] M. Von Kármán, Theoretical and experimental studies on laminar combustion and detonation waves, Symp. (Int.) Combust. (1953).

[43] J. Buckmaster, Edge-flames, Prog. Energy Combust. Sci. 28 (5) (2002) 435-475.

[44] T. Vedarajan, J. Buckmaster, Edge-flames in homogeneous mixtures, Combust. Flame 114 (1) (1998) 267-273.

[45] G.M. Makhviladze, V.I. Melikhov, Flame propagation in a closed channel with cold side walls, Chem. Eng. Sci. 27 (2) (1991) 176-183.

[46] A. Gruber, J.H. Chen, D. Valiev, C.K. Law, Direct numerical simulation of premixed flame boundary layer flashback in turbulent channel flow, J. Fluid Mech 709 (2012) 516-542.

[47] J.H. Lu, O. Ezekoye, R. Greif, R.F. Sawyer, Unsteady heat transfer during side wall quenching of a laminar flame, Symp. (Int.) Combust. 23 (1) (1991) 441-446. 